\title{
Emotional Variations in Professional Female Basketball Players
} Renan F. Correia (PG), Clóvis R. R. Haddad (PG), Júlia Barreira (PG), Paula Fernandes (PQ)

\section{Abstract}

There is vast interest on the correlates between athletic performance and athletes' emotional answers and adaptations to training and competition stimuli. This study had the objective of assessing emotional variations in the athletes composing the Brazilian Adult Female National Basketball Team during different periods of training over a four month span. In all, of the 33 subscales investigated in three different questionnaires, only six showed significant statistical difference during the period investigated. These results show that the athletes suffered no emotional variations during the different phases of physical training investigated. Key words: Emotional Variation, Sports Psychology, Basketball

\section{Introduction}

There is vast interest on the correlates between athletic performance and athletes' emotional answers and adaptations to training and competition stimuli. Sports Psychology, an interdisciplinary area with knowledge common to the areas of psychology and physical education, among others, offers tools to study this specific question and many more. ${ }^{2}$ Among various sports modalities, basketball arises scientific interest due to its game dynamics. ${ }^{3}$ This study had the objective of assessing emotional variation in the athletes composing the Brazilian Adult Female National Basketball Team during different periods of training for the 34th FIBA South American Championships and 2014 FIBA World Cup.

\section{Results and Discussion}

Three questionnaires were used for data collection during this study: RESTQ-76 (Recovery-Stress Questionnaire for Athletes) ${ }^{4}$, POMS (Profile of Mood States Questionnaire) ${ }^{5}$ and DALDA (Daily Analysis of Life Demands in Athletes). ${ }^{6}$ Seven samples were collected during a four month span and analyzed using one-tail ANOVA. Nineteen athletes participated in the study: Age $\bar{X} 24$ years (SD $= \pm 4.55$ years), height $\overline{\mathrm{X}} 1.82 \mathrm{~m}$ (SD $= \pm 0.08 \mathrm{~m})$, and national team basketball experience $\bar{X} 3.68$ years $(S D= \pm 4.25$ years). On the RESTQ-76, significant statistical difference $(p<0.05)$ was only found on only four of its 18 subscales during the study: Lack of Energy, Somatic Complaints, Somatic Relaxation, and Physical Fitness. On the POMS, the athletes displayed the iceberg profile (fig. 1) and significant statistical difference was only found in two of its seven subscales: Total Mood Disturbance and Fatigue. On the DALDA, no significant statistical difference was found in any of the subscales. In all, on the 33 subscales investigated (23 in the RESTQ-76, seven in the POMS, and three in the DALDA) only six showed significant statistical difference during the period investigated.
Image 1. Average POMS Scores

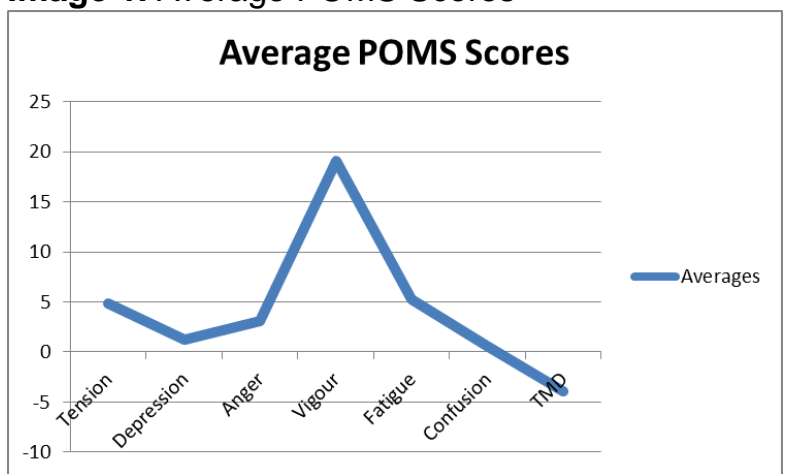

Conclusions

These results show that the athletes suffered no emotional variations during the different phases of physical training for the competitions in question. These results can be explained by the possibility that these athletes engage in emotional coping mechanisms optimally during these training periods.

\section{Acknowledgement}

The authors would like to thanks the National Counsel of Technological and Scientific Development (CNPQ) for the research funding that made this study possible.

\footnotetext{
${ }^{1}$ MACHADO, A. A Psicologia do esporte: da educação física escolar ao esporte de alto nível. Rio de Janeiro, RJ: Guanabara Koogan, 2006.

${ }^{2}$ WEINBERG, R. S., GOULD, D. Foundations of sport and exercise physiology Champaign: Human Kinetics, 2011.

${ }^{3}$ ROBAZZA, C. Relationship between biological markers and psychological states in elite basketball players across a competitive season; Psychology of Sport and Exercise 13 (2012) 509-517

${ }^{4}$ KELLMANN, M., KALLUS, K. W. The Recovery-StressQuestionnaire for Athletes: User Manual. Champaign: Human Kinetics. 2001

${ }^{5}$ MCNAIR, D.M. et al. Manual for the Profile of Mood States. San Diego, CA: Educational and Industrial Testing Services. 1971

${ }^{6}$ RUSHAL, B.S. A tool for measuring stress tolerance in elite athletes. Journal of Applied Sports Psychology, Philadelphia, v.2, p.51-66, 1990 .
} 